\title{
Nail Damage (Severe Onychodystrophy) Induced by Acrylate Glue: Scanning Electron Microscopy and Energy Dispersive X-Ray Investigations
}

\author{
Tudor Pinteala $^{a}$ Anca Eduard Chiriac $^{a} \quad$ Irina Rosca $^{b}$ Francesca Larese Filon $^{\mathrm{h}}$ \\ Mariana Pintealab Anca Chiriac ${ }^{c, d}$ Cristian Podoleanu $^{\text {e }}$ Simona Stolnicu $^{f}$ \\ Marius Florin Coros $^{9}$ Adina Coroaba ${ }^{b}$ \\ ${ }^{\mathrm{a}}$ Grigore T. Popa University of Medicine and Pharmacy, ${ }^{\mathrm{b}}$ Centre of Advanced Research in Bionanoconjugates and \\ Biopolymers, Institute of Macromolecular Chemistry Petru Poni, ' $D e p a r t m e n t$ of Dermatology, Nicolina Medical \\ Center, and ${ }^{\mathrm{d}}$ Department of Dermato-Physiology, Apollonia University, lasi, and ${ }^{\mathrm{e} C a r d i o l o g y}$ Clinic, ${ }^{\mathrm{f}}$ Pathology \\ Department, and ${ }^{9}$ Surgery Department, University of Medicine and Pharmacy of Targu-Mures, Tîrgu Mureș,

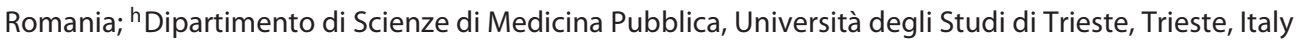

\section{Key Words}

Acrylate glue · Onycholysis · Scanning electron microscopy · Synthetic nails

\begin{abstract}
Background: Scanning electron microscopy (SEM) and energy dispersive X-ray (EDX) techniques have been used in various fields of medical research, including different pathologies of the nails; however, no studies have focused on obtaining high-resolution microscopic images and elemental analysis of disorders caused by synthetic nails and acrylic adhesives. Methods: Damaged/injured fingernails caused by the use of acrylate glue and synthetic nails were investigated using SEM and EDX methods. Results: SEM and EDX proved that synthetic nails, acrylic glue, and nails damaged by contact with acrylate glue have a different morphology and different composition compared to healthy human nails. Conclusions: SEM and EDX analysis can give useful information about the aspects of topography (surface sample), morphology (shape and size), hardness or reflectivity, and the elemental composition of nails.

(c) 2016 S. Karger AG, Basel
\end{abstract}

(c) 2016 S. Karger AG, Basel

2296-9195/16/0024-0137\$39.50/0

\section{Introduction}

Nails can be affected by natural factors, such as aging and infections, but also by chemical factors, such as most solvents found in nail polish and detergents [1].

Applied acrylic nails in conjunction with adhesives increase the bond between the natural nail and the synthetic one causing an alteration in nail flexibility, composition, and morphology. Rigidly adhered acrylics may also lead to serious breaking of nails, infection, and loss of the natural nail [2]. Allergic reactions to acrylic nails have also been reported, resulting in serious inflammation and thinning of the nail beds $[3,4]$.

Scanning electron microscopy (SEM) and energy dispersive X-ray (EDX) techniques are widely used in crystallography, geology, biology, medicine, nonbiological sciences, and other fields [5]. In recent years, EDX/SEM systems have become more and more attractive for the nanoscale investigation of biological structures in various medical fields (pathology of the heart $[6,7]$, kidney $[8,9]$, skin $[10,11]$, and hair [12-14]).

\section{KARGER}

E-Mail karger@karger.com www.karger.com/sad
Marius Florin Coros

Surgery Department

University of Medicine and Pharmacy of Targu-Mures

38 Gheorghe Marinescu Street, RO-540139 Tîrgu Mureș (Romania)

E-Mail corosmarius1@gmail.com 
SEM is a noninvasive technique which can be used for micro- and nanoscale observation and the characterization of inorganic or organic solids (revealing the microstructure, morphology, and fracture topography) [5, 1517], while the SEM technique can be used for the investigation of cells [18], tissues [5, 14, 19, 20], fragments of organs, or even organisms of suitable size [21, 22].

EDX is an analytical technique used for the elemental analysis or the chemical characterization of a sample, as well as in conjunction with the SEM technique [23]. EDX

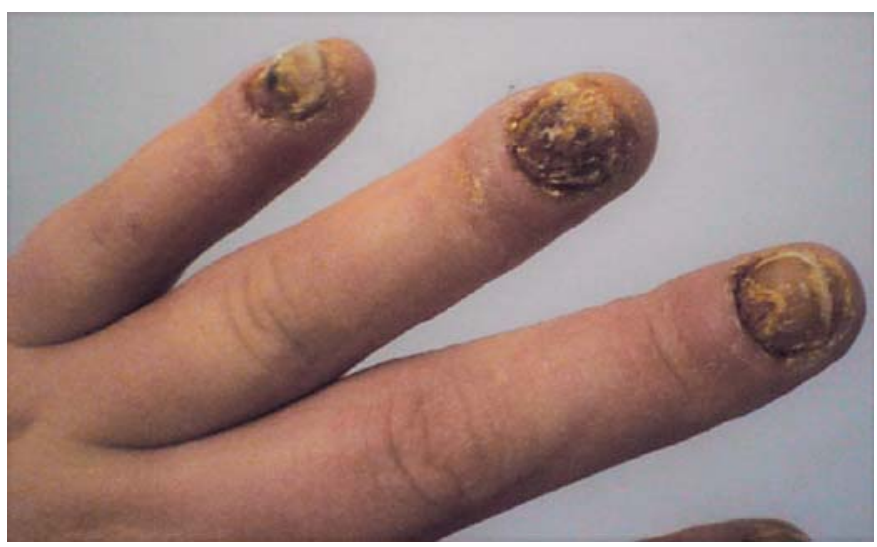

Fig. 1. Nails of the female patient damaged by acrylate nail glue. can only determine elements with an atomic number $>5$, but it is a versatile technique and allows gathering information about the distribution of chemical elements and the concentration profile of an element along a direction of interest in the sample; characteristics of the EDX spectrum of a sample can allow the calculation of the chemical composition. EDX has already become a useful research tool in the investigation of biological tissue surfaces [24-29].

\section{Materials and Methods}

A 24-year-old female presented to the Dermatology Department for severe degradation of the nail plates of all digits. The patient had no history of atopic dermatitis or allergic reactions, and no recent drug intake. Artificial nails had been applied, for the first time, a few days prior to the medical examination.

Clinical examination revealed severe degradation of the nail plates of all fingernails, associated with intense pain, slight pruritus on the tips of the digits, and paronychia (fig. 1). Full blood count was normal, and C-reactive protein level, erythrocyte sedimentation rate, urea, electrolytes, liver function tests, as well as urine analysis were within normal limits; screening for hepatitis virus $\mathrm{B}$ and $\mathrm{C}$ was negative. Mycological examination and fungal culture of scrapings from nail plates were repeatedly negative. The patient did not approve of nail biopsy due to intense local pain and anxiety. Patch tests with extended European Baseline Series and with methyl methacrylate $2 \%$ and toluenesulfonamide formaldehyde resin 10\% (Chemotechnique) were negative.
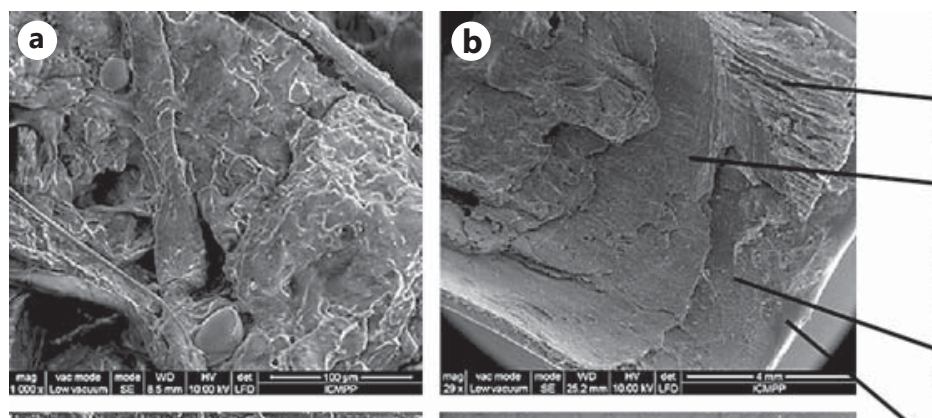

(b1)
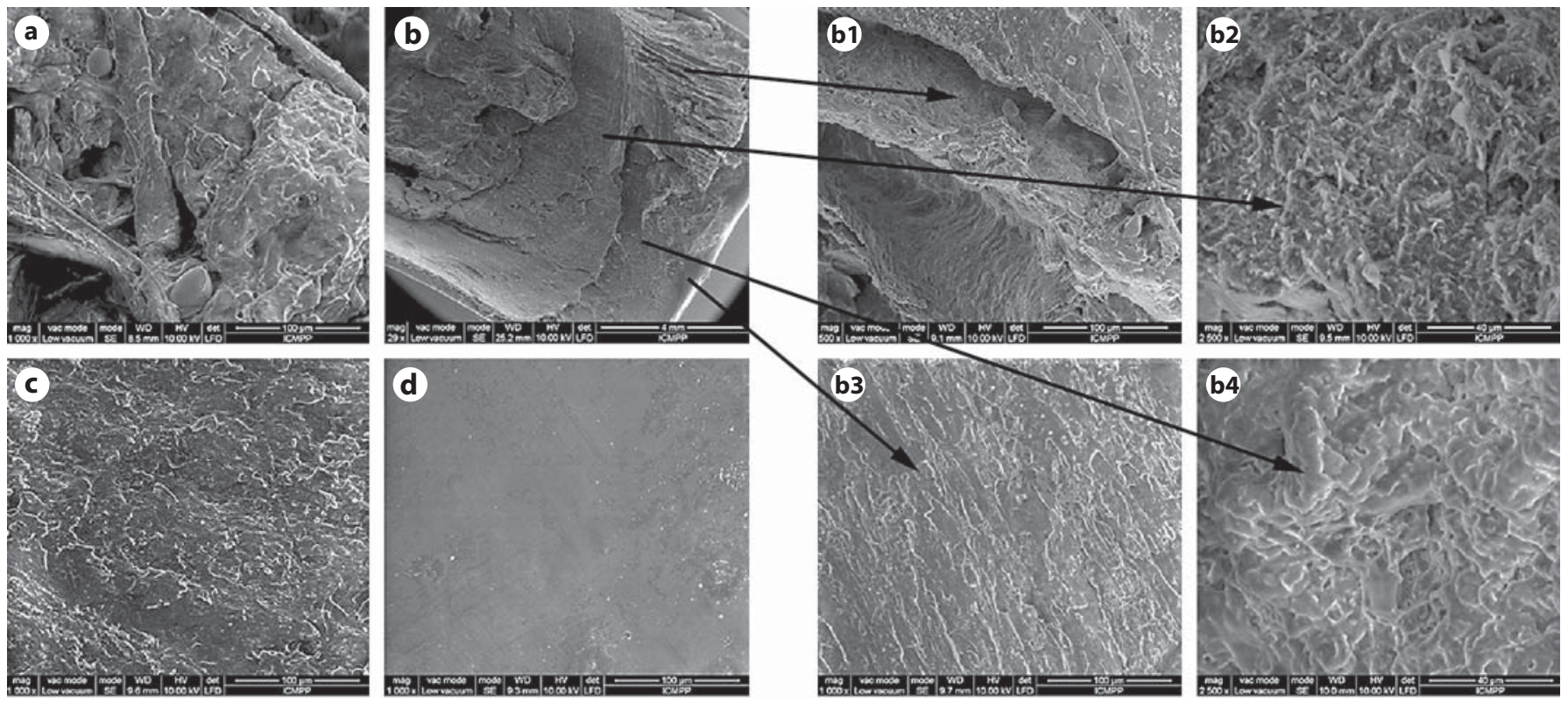
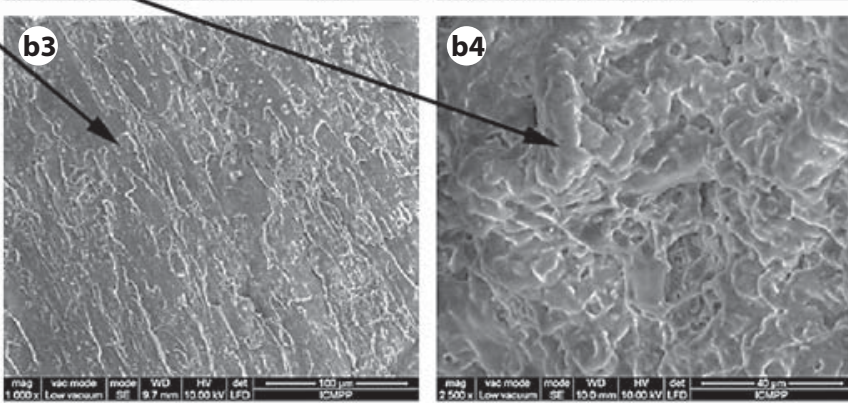

Fig. 2. SEMs of the nails. a Affected dorsal human nail due to acrylate glue. $\mathbf{b}$ A piece of damaged nail glued to the synthetic one. $\mathbf{c}$ Healthy human nail. d Synthetic nail. Insets for b: the intermediate layer (b1), the bottom layer (b2), the synthetic nail area (b3), and the glue area (b4). 
Slight improvement was obtained with systemic antihistamines, potent topical steroid cream, and removal of the artificial nails. The patient was followed up for 3 months with full recovery.

The analysis of the damaged fingernail was compared to a healthy nail taken from a donor of the same age and gender, using SEM and EDX techniques.

\section{SEM and EDX Analysis}

Morphological studies were performed using a Quanta 200 SEM equipped with an Oxford INCA EDX system. In order to prepare samples for SEM and EDX, small cuttings from the control nail as well as from the synthetic and damaged nails of the patient were deposited on aluminum stubs with double-sided carbon tape. Investigations were performed in low vacuum mode using a secondary electron detector (large field detector) at an accelerating voltage of $10 \mathrm{kV}$. Samples were prepared by cutting pieces of nails in squares of $2 \times 2 \mathrm{~mm}$.

\section{Results}

SEM analysis of the nail affected by acrylate glue (fig. $2 \mathrm{a}$ ), a piece of the damaged nail glued to the synthetic one (fig. 2b), the healthy human control nail (fig. 2c), and the synthetic nail (fig. $2 \mathrm{~d}$ ) was performed in order to evaluate the changes induced by applying acrylate adhesive on the human nail. Elemental analysis was obtained by the EDX method, as shown in figure 3 .

\section{Discussion}

Recent studies have shown that acrylic nails and adhesives may induce fingertip and periungual dermatitis, onycholysis, and nail dystrophy $[3,4]$, as well as allergic reactions [30].
Fig. 3. EDX spectra of the nails. a Healthy human nail. b Layer of damaged human nail. c Synthetic nail. d A piece of the damaged nail glued to the synthetic one.

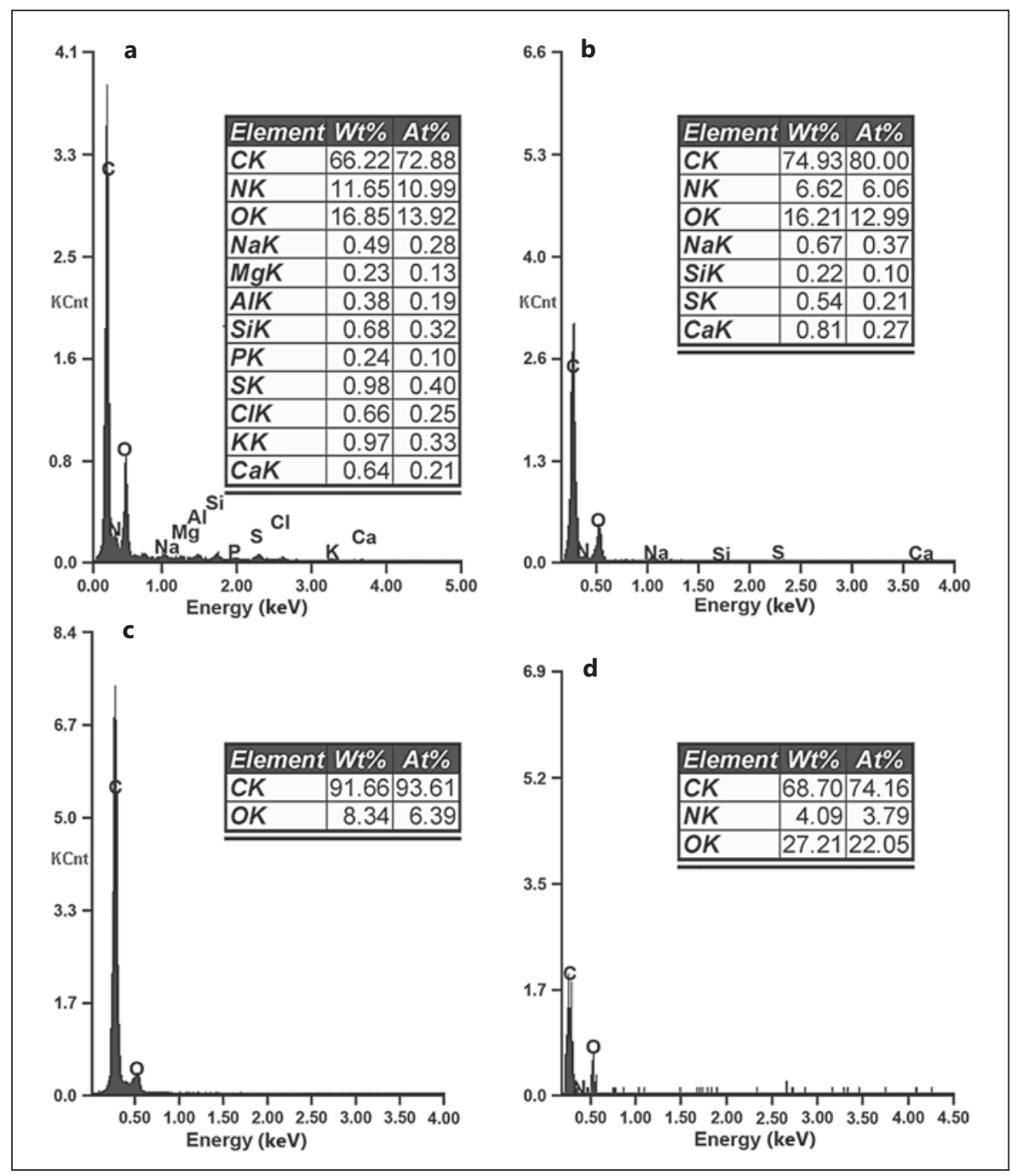

Severe Onychodystrophy Caused by Cyanoacrylate Nail Glue
Skin Appendage Disord 2016;2:137-142 DOI: $10.1159 / 000450791$ 


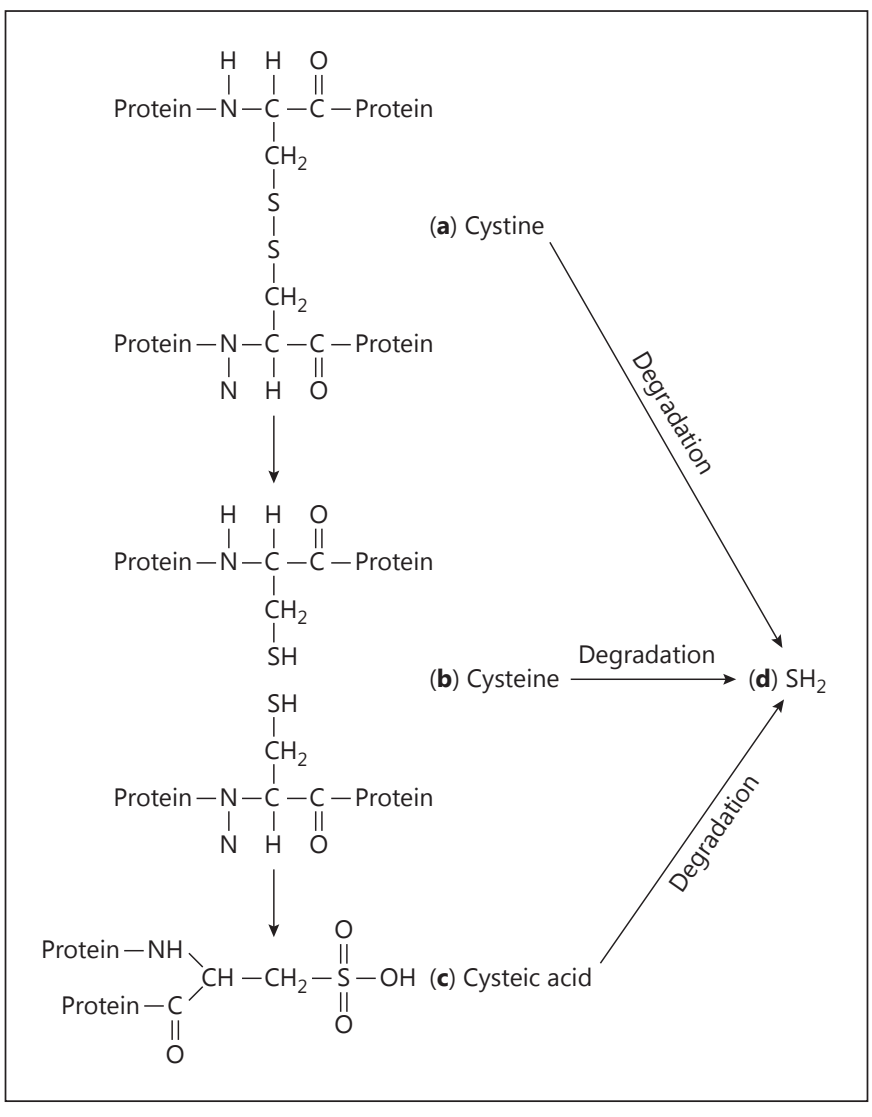

Fig. 4. The principal keratin structural units and the schematic mechanism of disulfide bridge degradation. This figure shows cystine (a), cysteine (b), cysteic acid (c), and the degradation of cystine, cysteine, and cysteic acid (d).

The present study investigated the effects induced by acrylic glue, which was applied to stick the synthetic nail to the normal human one.

SEMs at the same magnification of the affected nail of the patient (fig. 2a) and the piece of the damaged nail glued to the synthetic one (fig. 2b) compared to those of the normal (fig. 2c) and synthetic (fig. 2d) nails clearly reveal that the morphology is dramatically changed due to the aggressive action of acrylic adhesive on fingernails.

The SEM image of the affected nail appears to be rough, with globular domains (fig. 2a), while the healthy nail (fig. 2c) is uniform, composed of flat, overlapping slate-like sheets oriented in the plane of the nail, with only occasional separation of one or more corneocytes [31]. The surface of the synthetic acrylic nail (fig. 2d) has a different morphology compared to the damaged and normal nails, showing a flat layer with rare globular do- mains. A close examination of the piece of damaged nail glued to the synthetic one (fig. 2b), in different areas, highlighted the fact that an intermediate layer presents a fibrillar morphology (fig. 2b1) and the bottom layer presents tile-like cells with randomly oriented fibrous keratin (fig. 2b2). SEMs of the synthetic nail (fig. 2b3) and glue (fig. 2b4) show amorphous morphology with weak globular domains, similar to the synthetic nail alone (fig. 2d).

EDX analysis of the synthetic nail (fig. 3c) only shows 2 elements, while the normal nail reveals the presence of 12 elements in different concentrations (fig. 3a): carbon (C) $72.88 \%$ (atomic concentration), oxygen (O) $13.92 \%$, nitrogen $(\mathrm{N})$ 10.99\%, sodium $(\mathrm{Na}) 0.28 \%$, magnesium (Mg) $0.13 \%$, aluminum (Al) $0.19 \%$, silicon $(\mathrm{Si}) 0.32 \%$, phosphorous (P) $0.10 \%$, sulfur $(\mathrm{S}) 0.40 \%$, potassium $(\mathrm{K})$ $0.33 \%$, calcium $(\mathrm{Ca}) 0.21 \%$, and chlorine $(\mathrm{Cl}) 0.25 \%$.

The elemental analysis of the synthetic nails only showed 2 major elements: C (93.61\%) and O (6.39\%) (fig. 3c).

The damaged nail had a different composition (fig. 3b), containing $\mathrm{C}(80.00 \%)$ as the dominant element, as well as $\mathrm{O}(12.99 \%), \mathrm{N}(6.06 \%), \mathrm{Na}(0.37 \%), \mathrm{Si}(0.10 \%), \mathrm{S}$ $(0.21 \%)$, and $\mathrm{Ca}(0.27 \%)$. The concentration of $\mathrm{Na}$ was increased in the damaged nail, $\mathrm{Al}$ was absent (possibly correlated with the less hardening nail) [32], whereas the concentrations of Si and S were low. The diminished content of $S$ in the injured nail may be explained by the action of chemical compounds that can cause the destruction of the nail, attacking the disulfide bridges, which are responsible for the stability of keratin nail matrix (fig. 4). Nail keratin contains cysteine (fig. 4a), which is responsible for the stability of the nail matrix along with the inter- and intramolecular hydrogen bonds produced by amide groups of keratin [33].

In the present case, disulfide groups of cystine units were transformed by reduction reactions in thiol groups of cysteine (fig. 4b); some of them were oxidized to sulfate groups of cysteic acid (fig. 4c) and later to volatile degradation products, such as hydrogen sulfide $\left(\mathrm{SH}_{2}\right)$ (fig. 4d) [34]. As a consequence of these reactions, the stability of the nail was reduced and the content of $\mathrm{S}$ decreased.

Elemental analysis and EDX spectra of the damaged nail glued to the synthetic one (fig. $3 \mathrm{~d}$ ) proved the presence of $\mathrm{C}$ and $\mathrm{O}$ elements in high concentrations and of $\mathrm{N}$ in a lower amount. The presence of $\mathrm{N}$ was the indication that the nail piece was glued to the artificial fingernail through the acrylic adhesive. 


\section{Conclusions}

EDX and SEM methods were used in a case of severe degradation of nail plates induced by contact with acrylic nail glue comparing normal and synthetic nails.

The results obtained by EDX and SEM methods were complementary and consistently demonstrated that: (a) acrylate nail glue, in particular, produces degradation of the disulfide bridge of cystine units from protein to thiol groups, and some of them into sulfite groups or a complete degradation, producing a destabilization of the healthy nail matrix with changes in surface morphology in terms of uniformity, density, and roughness; (b) acrylate nail glue causes loss of $\mathrm{Si}$ (reducing brightness), which increases the content of $\mathrm{Na}$ and $\mathrm{Ca}$; and (c) loss of $\mathrm{Al}$ (indicating less nail hardening).

We present a case of acute and severe degradation of nail plates by direct contact with acrylates in the absence of any allergic reactions. EDX and SEM proved that the nail degradation was induced by contact with acrylate nail glue. Further studies using the same methods with differ- ent nail pathology could be of great value for a diagnosis and understanding of the mechanisms of nail destruction.

\section{Acknowledgement}

We thank Adrian Naznean from the Foreign Language Department, University of Medicine and Pharmacy of Tirgu Mures, for having carefully corrected the manuscript.

The research received financial support from PN-III-P3-3.6H2020-2016-0011 and H2020 SupraChem Lab projects.

\section{Statement of Ethics}

Written informed consent was obtained from the patient, and the study was performed according to the Declaration of Helsinki.

\section{Disclosure Statement}

The authors declare no conflicts of interest.

\section{References}

1 Tosti A, Iorizzo M, Piraccini BM, Starace M: The nail in systemic diseases. Dermatol Clin 2006;24:341-347.

2 Ramos L, Cabral R, Gonçalo M: Allergic contact dermatitis caused by acrylates and methacrylates - a 7-year study. Contact Dermatitis 2014;71:102-107.

3 Uter W, Geier J: Contact allergy to acrylates and methacrylates in consumers and nail artists - data of the Information Network of Departments of Dermatology, 2004-2013. Contact Dermatitis 2015;72:224-228.

4 Kwok C, Money A, Carder M, Turner S, Agius R, Orton D, Wilkinson M: Cases of occupational dermatitis and asthma in beauticians that were reported to The Health and Occupation Research (THOR) network from 1996 to 2011. Clin Exp Dermatol 2014;39: 590-595.

5 Goldstein J, Newbury DE, Echlin P, Joy DC, Fiori C, Lifshin E: Scanning Electron Microscopy and X-Ray Microanalysis: A Text for Biologists, Materials Scientists, and Geologists. New York, Springer Science and Business Media, 2013, p 679.

6 Saunders R, Amoroso M: SEM investigation of heart tissue samples. J Phys Conf Ser 2010; 241:012023.

7 Mudhar HS, Wagner BE, Suvarna SK: Electron microscopy of myocardial tissue. A nine year review. J Clin Pathol 2001;54:321-325.
8 Arkill KP, Qvortrup K, Starborg T, Mantell JM, Knupp C, Michel CC, Harper SJ, Salmon AH, Squire JM, Bates DO, Neal CR: Resolution of the three dimensional structure of components of the glomerular filtration barrier. BMC Nephrol 2014;15:24.

9 Nyska A, Cummings CA, Vainshtein A, Nadler J, Ezov N, Grunfeld Y, Gileadi O, Behar V: Electron microscopy of wet tissues: a case study in renal pathology. Toxicol Pathol 2004;32:357-363.

10 Liem PH, Morimoto N, Mahara A, Jinno C, Shima K, Ogino S, Sakamoto M, Kakudo N, Inoie M, Kusumoto K, Fujisato T, Suzuki S, Yamaoka T: Preparation of inactivated human skin using high hydrostatic pressurization for full-thickness skin reconstruction. PLoS One 2015;10:e133979.

11 Pirisinu M, Mazzarello V: 3D profilometric characterization of the aged skin surface using a skin replica and alicona Mex software. Scanning 2016;38:213-220.

12 Stecksén-Blicks C, Kieri CF, Hägg D, SchmittEgenolf M: Hair shaft structures in EDAR induced ectodermal dysplasia. BMC Med Genet $2015 ; 16: 79$.

13 Turkmenoglu FP, Kasirga UB, Celik HH: Ultra-structural hair alterations of drug abusers: a scanning electron microscopic investigation. Int J Clin Exp Med 2015;8:8803-8811.
14 Solovan C, Doroftei F, Pinteala M, Chiriac A, Cristea C: Scanning electron microscopic examination of the hair shaft abnormalities in Netherton's syndrome. Int J Dermatol 2015; 54:693-694.

15 Reimer L: Scanning Electron Microscopy: Physics of Image Formation and Microanalysis. New York, Springer Science and Business Media, 1998, p 552.

16 Doroftei F, Damaceanu MD, Simionescu BC, Mihai M: Calcium carbonate microparticle growth controlled by a conjugate drug-copolymer and crystallization time. Acta Crystallogr Sect B Struct Sci Cryst Eng Mater 2014; 70:227-235.

17 Drobota M, Aflori M, Stoica I, Doroftei F: Surface characterization of amine functionalized pet films after collagen immobilization. Rev Roum Chim 2013;58:203-207.

18 Gadelha APR, Benchimol M, de Souza W: Helium ion microscopy and ultra-high-resolution scanning electron microscopy analysis of membrane-extracted cells reveals novel characteristics of the cytoskeleton of Giardia intestinalis. J Struct Biol 2015;190:271-278.

19 Orime M, Ushiki T, Koga D, Ito M: Threedimensional morphology of touch domes in human hairy skin by correlative light and scanning electron microscopy. J Invest Dermatol 2013;133:2108-2111.
Severe Onychodystrophy Caused by

Cyanoacrylate Nail Glue
Skin Appendage Disord 2016;2:137-142 DOI: 10.1159/000450791 
20 Sharma G, Kakkar P, Vats A: A comparative SEM investigation of smear layer remaining on dentinal walls by three rotary NiTi files with different cross sectional designs in moderately curved canals. J Clin Diagn Res 2015; 9:ZC43-ZC47.

21 Pawley J, Schatten H: Biological Low-Voltage Scanning Electron Microscopy. New York, Springer Science and Business Media, 2007, p 323.

22 Al-Nazhan S, Al-Sulaiman A, Al-Rasheed F, Alnajjar F, Al-Abdulwahab B, Al-Badah A: Microorganism penetration in dentinal tubules of instrumented and retreated root canal walls. In vitro SEM study. Restor Dent Endod 2014;39:258-264.

23 Bell DC, Garratt-Reed AJ: Energy Dispersive $\mathrm{X}$-Ray Analysis in the Electron Microscope, ed 1. Oxford, Garland Science, 2003, p 160.

24 Roomans GM, Afzelius BA, Kollberg H, Forslind B: Electrolytes in nails analysed by $\mathrm{X}$-ray microanalysis in electron microscopy. Considerations on a new method for the diagnosis of cystic fibrosis. Acta Paediatr Scand 1978;67:89-94.
25 Scimeca M, Orlandi A, Terrenato I, Bischetti S, Bonanno E: Assessment of metal contaminants in non-small cell lung cancer by EDX microanalysis. Eur J Histochem 2014;58: 2403.

26 Grunenwald A, Keyser C, Sautereau AM, Crubézy E, Ludes B, Drouet C: Novel contribution on the diagenetic physicochemical features of bone and teeth minerals, as substrates for ancient DNA typing. Anal Bioanal Chem 2014;406:4691-4704.

27 Boonrungsiman S, Fearn S, Gentleman E Spillane L, Carzaniga R, McComb DW, Stevens MM, Porter AE: Correlative spectroscopy of silicates in mineralised nodules formed from osteoblasts. Nanoscale 2013;5:75447551.

28 Kodaka T, Debari K, Sano T, Yamada M: Scanning electron microscopy and energydispersive X-ray microanalysis studies of several human calculi containing calcium phosphate crystals. Scanning Microsc 1994;8:241256; discussion 256-257.
29 Torjussen W, Haug FM, Olsen A, Andersen I: Topochemistry of trace metals in nasal mucosa. Potentialities of some histochemical methods and energy dispersive X-ray microanalysis. Acta Histochem 1978;63:11-25.

30 Tammaro A, Narcisi A, Abruzzese C, Giulianelli V, Madjaroff R, Parisella FR, Cortesi G: Fingertip dermatitis: occupational acrylate cross reaction. Allergol Int 2014;63:609-610.

31 Kobayashi Y, Miyamoto M, Sugibayashi K, Morimoto Y: Drug permeation through the three layers of the human nail plate. J Pharm Pharmacol 1999;51:271-278.

32 Dittmar M, Dindorf W, Banerjee A: Organic elemental composition in fingernail plates varies between sexes and changes with increasing age in healthy humans. Gerontology 2008;54:100-105.

33 Ogura R, Knox JM, Griffin AC, Kusuhara M: The concentration of sulfhydryl and disulfide in human epidermis, hair and nail. J Invest Dermatol 1962;38:69-75.

34 Oguri T, Schneider B, Reitzer L: Cysteine catabolism and cysteine desulfhydrase (CdsH/ STM0458) in Salmonella enterica serovar typhimurium. J Bacteriol 2012;194:4366-4376. 